\title{
Trabalho escravo e infantil no discurso da mídia do Sudeste brasileiro: Uma identidade "bárbara" da sociedade paraense?
}

\author{
Slave and child labor in the Southeastern Brazil media speech: \\ A cruel identity of the Paraense society?
}

\author{
Marcos André Dantas da CUNHA* \\ Universidade Federal do Pará (UFPA)
}

\begin{abstract}
RESUMO: Pautado na Análise do Discurso de Linha francesa, influenciada por Pechêux (2002) e mais especificamente por Foucault (2008), este artigo apresenta o debate em torno do conceito de discurso, tensionado entre a materialidade linguística e o acontecimento histórico. Também ressalta a concepção de sujeito a partir da noção de poder fragmentado foucaultiana. Considerando esta noção, focaliza a produção da identidade como uma das possibilidades de reconhecimento do sujeito, moldado pela instabilidade consumista na modernidade atual (BAUMAN, 2001). A partir daí, localiza a identidade regional paraense no bojo do debate das diferenças entre as regiões brasileiras, pensando o regional se constituindo na relação com o nacional (HALL, 2006). Ao analisar a produção da identidade, busca destacar na mídia - enquanto um importante dispositivo de poder - (AGAMBEN, 2009) a temática repetível e reincidente do trabalho escravo e infantil, marcando uma identidade, talvez, "periférica e bárbara" do estado do Pará.
\end{abstract}

PALAVRAS-CHAVE: Discurso. Sujeito. Identidade. Mídia. Pará.

ABSTRACT: Based on French Style Discourse Analysis, influenced by Pecheux (2002) and in more detail by Foucault (2008), this paper presents the debate around the concept of discourse, located between the materiality of language and the historical episode. It also emphasizes the concept of subject from the notion of Foucauldian fragmented power. Considering this notion, it focuses on the identity production as one of the possibilities of subject recognition, shaped by consumerist instability in current modernity (BAUMAN, 2001). Thereafter, it locates the Pará regional identity in the midst of the debate on the differences of the Brazilian regions, considering the regional constituting itself in the relation with the national (HALL, 2006). By analyzing the production of identity it seeks to highlight the media as a major power device (AGAMBEN, 2009) the repeatable and recurrent theme of slave and child labor, marking a, possibly, "Peripheral and barbaric" identity of the state of Pará.

KEYWORDS: Speech. Subject. Identity. Media. Pará.

\footnotetext{
* Doutorado em Língua Portuguesa e Linguística; professor Adjunto de Linguística da Universidade Federal do Pará (UFPA), campus de Castanhal. Castanhal-PA - Brasil. E-mail: madc@ufpa.br. 


\section{Introdução: $O$ discurso, o sujeito e a produção da identidade ${ }^{1}$}

Levando-se em consideração o aspecto ideológico atravessando o linguístico, indaga-se se a língua seria afinal estrutura ou acontecimento? A resposta para a indagação quanto ao fato do discurso pertencer à ordem da estrutura ou do acontecimento logo aponta para a heterogeneidade enquanto constitutiva do discurso. "Há, em todo discurso, um jogo entre a historicidade e a materialidade, entre a descontinuidade do histórico e a regularidade da linguagem" (GREGOLIN, 2009, p. 47).

Os sentidos do discurso se produzem no tensionamento entre a dispersão do acontecimento e a regularidade da materialidade estrutural da língua. Não separadamente, mas simultaneamente, o discurso se faz materialidade e historicidade, estrutura e acontecimento. No entanto, nos estudos linguísticos há uma tendência em se assombrear o acontecimento pela estrutura. Acerca disto vem dizer Pêcheux (2002, p.56): "O gesto que consiste em inscrever tal discurso dado em tal série, a incorporá-lo a um 'corpus', corre sempre o risco de absorver o acontecimento desse discurso na estrutura da série [...] desembocaria em um apagamento do acontecimento" (PÊCHEUX, 2002, p. 56).

Dado o caráter formalista do estruturalismo, destaca-se a preocupação em inserir o acontecimento numa estrutura discursiva, enfatizando-se o linguístico, muitas vezes em detrimento do histórico. Isto tenderia a neutralizá-lo. No entanto, não se pode negar que o sentido transitaria entre o acontecimento e a estrutura, entre o si e o outro. Então, o discursivo não deixaria de estar presente na estrutura. Desse modo, talvez a mesma concepção de incompletude presente na matriz teórica do estruturalismo seja a que venha a caracterizar a perspectiva foucaultiana.

Ainda que a perspectiva estrutural tenha se detido na forma, o sentido constituído na incompletude entre as diferenças se faz próximo a esse campo. Essa percepção se mostrou como central na obra teórica desenvolvida por Foucault. Para este autor, a necessidade de completude se deve ao reflexo da modernidade de hoje, marcando o período atual (idade da Interpretação), caracterizando-se pela historicização da cultura ocidental.

O sentido outro está naquilo que não vem expresso na materialidade da palavra, ou seja, nos implícitos. Também na ausência significativa de uma materialidade se constitui o sentido, a partir da alusão. Desse modo "todo enunciado é intrinsecamente suscetível de tornar-se outro, diferente de si mesmo, se deslocar discursivamente de seu sentido para derivar para um outro" (PÊCHEUX, 2002, p. 53).

Pelo fato, então, de um enunciado estar em outro como numa relação metonímica, quando procedemos à descrição de um enunciado ou de uma série deles, buscamos neles não um sentido a ele restrito, mas pontos em movimento a serem interpretados. Nesse esforço do delineamento de si, para descortinar-se o outro, realiza-se a metodologia da descrição/interpretação do discurso.

A presença do "outro" evidenciado em Pêcheux (2002) o aproxima das concepções foucaultianas de sujeito cindido. Nesse autor, o sujeito dividido se constitui num processo de rebeldia, de resistência a uma exploração do trabalho por um poder concentrado. Já para Foucault, a resistência aparece em diversas ordens e níveis, pois "parte da idéia de 'micropoderes' que não descartam o poder do Estado, mas o ultrapassam" (GREGOLIN, 2004, p. 143).

\footnotetext{
${ }^{1}$ Este artigo constitui-se em parte da temática desenvolvida em nossa tese de doutorado defendida no programa de Pós-Graduação Strictu Sensu em Língua Portuguesa e Linguística da Universidade Estadual Paulista "Júlio de Mesquita Filho"- UNESP/Araraquara (2011), sob a orientação da professora Dra Maria de Fátima do Rosário Valencise Gregolin.
} 
Para Foucault (2008), o sujeito é dividido entre forças conscientes e inconscientes. Entre essas se estabelecem relações de poder, atravessando nosso corpo e nossas atitudes. Mesmo nossos desejos mais inconscientes são conduzidos por relações de poder. Ao ressaltar as relações de poder sobre um poder concentrado, coloca-se "em jogo relações entre sujeitos e os discursos refletem os lugares desses sujeitos" (FERNANDES; ALVES JÚNIOR, 2009, p. 103).

Considerando-se que há vários lugares de realização do discurso, a cada um desses refere-se um determinado, porém não tão delimitado, lugar de discurso, daí podemos chegar até o conceito de formação discursiva. Uma série de enunciados delimitada por dado objeto, conceitos, estratégias poderia ser compreendido como uma formação discursiva. A partir deste conceito, embasado na arqueologia foucaultiana, acerca do discurso nos diz Baronas (2004, p. 50) como "um conjunto de práticas discursivas que instauram os objetos sobre os quais enunciam, circunscrevem os conceitos, legitimam os sujeitos enunciadores e fixam as estratégias sérias que rareiam os atos discursivos".

Então, o discurso não seria nem delimitado pela oralidade ou pela escrita, podendo ser repetível, retomado, mas sempre inédito pela vinculação com a história. $\mathrm{O}$ discurso seria, segundo Foucault (2008, p. 133) "constituído de um número limitado de enunciados para os quais podemos definir um conjunto de condições de existência".

Conforme nos diz Certeau (2006, p. 314), pensando no discurso inserido num debate em torno da materialidade expressa da cultura: "É necessário morrer de corpo para que nasça a escrita". Nesse sentido, para espreitarmos o discurso diante de uma materialidade linguística expressa nos enunciados, devemos buscar o outro, levantarmos o sentido que se constrói a partir do atravessamento do linguístico. Buscar o discurso é escavar o sentido que se constrói não somente para além dos fatos restritamente delimitados como também para além das palavras ou signos materialmente expressos.

Para a teoria do discurso há um sujeito incompleto, constituído de partes, em heterogeneidades de lugares, delimitado por diversos dispositivos conforme veremos a seguir. Tal sujeito heterogêneo ocupando um lugar central na enunciação discursiva responde à noção de identidade sugerida por Bauman (2001) e Hall (2006).

$\mathrm{Na}$ sociedade de consumo da modernidade atual, aquele que não se enquadra no consumismo pode ser tomado como diferente, até mesmo estranho, ou mesmo ameaçador. Um comportamento delimitado pelo poder de ter, de possuir, que se faz moldador das subjetividades, produtor de um individualismo exacerbado. O distinto seria considerado "um ermo repleto de emboscadas e conspirações e fervilhante de inimigos que brandem o caos como sua arma principal" (BAUMAN, 2001, p. 197). Daí a necessidade de os indivíduos abrigarem-se protegidamente em seus espaços culturais. Seria preciso enquadrar-se de modo acelerado nessa mobilidade constante do consumo sempre novo, disposto sempre ao mais.

Desse modo, seriam as identidades móveis as dominantes. Elas não permitiriam a permanência, a delimitação, mas a busca desenfreada de um novo que em sua conquista já se fará ultrapassado. Não se delimitam as margens entre o que seria meu e do outro, assim "as margens incharam rapidamente, invadindo as áreas centrais da coabitação humana" (BAUMAN, 2001, p. 24).

$\mathrm{Na}$ modernidade de hoje favorecida pelo discurso da modernidade que destituiria os limites, possibilitando uma oferta sempre possível de ser adquirida, a possibilidade de possuir se mostraria ilimitada e então com sentido fugaz. Assim diz Cunha (2011, p.115) "Desse modo, as identidades se fazem não pelo pertencimento a um espaço, uma comunidade, uma região, estado, nação, mas sim pela maior possibilidade de fazer das coisas seu objeto, até mesmo dos demais sujeitos, inclusive, objetos de pertencimento". 
Ainda que a relação escrava possa parecer distante das sociedades na modernidade atual, ela ainda se faz presente, ou melhor, se consuma de modo muito mais eficaz pela propagada "venda" da liberdade absoluta. Nas diferenças delimitadas e visibilizadas entre aquilo que se classificaria como "centro" e "periferia" brasileira estaria realçada a noção do que se entenderia por barbárie. Esta estaria identificada com o distanciamento de dados valores característicos da civilização. Entretanto, os valores tomados como característicos da modernidade atual poderiam na verdade ser a ilustração de uma sociedade marcada pela exclusão, ou mesmo por uma escravização sutil e perigosa dos sujeitos.

Dizer quem seria "centro" ou "periferia" naquilo que se constituiria uma nação, ou mais detidamente, delimitar e localizar espaços parece já pressupor classificações, assim, definir uma cultura, no afã, talvez acolhedor, de se estabelecer uma homogeneidade, de se buscar uma identidade. O todo pressupõe as partes. Estas são por onde se produzem as diferenças.

Nessas as relações de poder se fazem exercidas. O si se coloca e se visibiliza na relação com o outro. Para Hall (2006, p. 48), "as identidades nacionais não são coisas com as quais nós nascemos, mas são formadas e transformadas no interior da representação". No entanto, como ressaltamos, uma unidade se pauta em outras unidades já delimitadas e em sua constituição produzem outras: um encontro que produz semelhanças e confrontos. Então, assim, "em vez de pensar as culturas nacionais como unificadas, deveríamos pensálas como constituindo um dispositivo que representa a diferença como unidade ou identidade" (HALL, 2006, p. 62).

Pensando em torno da relação entre sujeito e identidade, pertinentes para a temática desenvolvida neste trabalho, Fernandes e Alves Júnior (2009, p. 106) esclarecem: "o sujeito, assim como sua identidade, está sempre em movimento, desloca-se constantemente de um lugar para outro, e cada lugar ocupado por ele o faz mostrar-se outro, diferente de si, atestando o lugar contraditório e inacabado da identidade".

Desse modo, a não unicidade e centramento do sujeito discursivo repercute em seu caráter fragmentado. Isto com bem maior evidência dada a efemeridade da sociedade contemporânea, determinada pela produção e consumo exacerbados. Assim, o poder do ter e acumular atravessa até mesmo a intimidade das identidades.

O sujeito em sua categorização discursiva e as identidades em sua constituição social, e talvez como produto de uma auto-imagem, seriam delimitados pelos dispositivos. Foucault (2008) define dispositivos como uma diversidade de mecanismos pelos quais o poder se inscreve nas relações sociais, produzindo e transformando subjetividades. Mais contemporaneamente, Agamben $(2009$, p. 40), contribuindo com o conceito foucaultiano, vem esclarecer "[...] qualquer coisa que tenha de algum modo a capacidade de capturar, orientar, determinar, interceptar, modelar, controlar e assegurar os gestos, as condutas, as opiniões dos seres viventes".

\section{Os dispositivos de poder e a mídia}

Os dispositivos numa heterogeneidade se fariam tanto pelos mais complexos quanto pelos mais sofisticados, individualizados e até íntimos meios tecnológicos, no caso, a linguagem. Um tipo de dispositivo que interessa diretamente para a temática aqui proposta e que se faz de modo bastante imerso nas relações de poder social, estando presente, circulando entre muitos outros dispositivos. A mídia, dado seu poder de penetração aparece destacada por Coracini $(2009$, p. 25): 
[...] colocados em prática de agenciamentos (tecnologias do eu, dentre as quais se encontra a mídia, talvez a mais poderosa nos dias de hoje, a ponto de podermos considerá-la como um poderoso substituto das instituições tradicionais, como a igreja e a família) que dão lugar a um eu inserido num dado momento histórico-social.

A mídia possibilitaria ao sujeito acessar traços que o faz se identificar com outro em processo de inacabamento e constituição. A mídia seria o outro diante de um sujeito "eu" sempre em processo, fazendo-se completude. Não somente sendo o outro, mas também na busca de se fazer com o outro unidade, estabelecer conexões onde houvesse distanciamento, construir elos de relações nacionais, com esse papel se estabeleceu a mídia, por exemplo, na América Latina. Esse papel de certo modo homogeneador da mídia, diante das diferenças intra-regionais, é historicizado por Martin-Barbero (2009, p. 221) " [...] superar as fragmentações que originaram as lutas regionais [...] tornando-lhe possível a comunicação entre várias regiões - rodovias, estradas de ferro, telégrafos, telefones e rádio -, mas acima de tudo das regiões com o centro, com a capital".

Nesse processo a tecnologia que se mostra bastante assimilada pelos meios midiáticos se faz determinante. Nas relações de poder entre nações e regiões, o outro que se faz forte poderá a vir ditar a voz, ou melhor, o discurso, inclusive da mídia. Desse modo: "Grande parte do que se produz e se vê nos países periféricos é projetada e decidida [...] nas editoras e nas agências de notícias dos Estados Unidos e da Europa" (CANCLINI, 2008, p. 130).

Os jornais impressos, pela sua própria caracterização, se constituindo em eficiente circulação, produzem e colocam em circuito notícias, enfim, o que chamaremos de discurso, em sintonia com os interesses econômicos mais dominantes. Sobre isto nos fala Marcondes Filho (1989, p. 11):

O jornalismo, via de regra, atua junto com grandes forças econômicas e sociais: um conglomerado jornalístico raramente fala sozinho. Ele é ao mesmo tempo a voz de outros conglomerados econômicos ou grupos políticos que querem dar às suas opiniões subjetivas e particularistas o foro de objetividade.

\section{O paradoxo centro/periferia e civilização/barbárie}

O poder se realiza de modo difuso, ou ainda, as relações verificadas numa dada realidade podem se repetir de modo similar em outra, verificando-se certos espaços de dominação quase que repetidos, em distintas conjunturas, porém precipitados por certas objetivações históricas. Assim, essa relação de certa subordinação imperialista, observada da Europa e América do Norte (EUA) concernente a muitos países, parece fragmentar-se em focos de micropoderes constituídos intranacionalmente.

Aquilo que se observa em nível mais macro entre continentes gera, de certo modo, repercussão nos países e internamente nas nações. Dessa maneira, verificam-se certas relações de dominação e imperialismo entre os estados mais privilegiados economicamente e os menos privilegiados, conforme já indicamos anteriormente.

$\mathrm{Na}$ atualidade, tendo em vista as diferenças regionais, principalmente do Sudeste/Sul em relação ao Norte brasileiro, considerando a proeminência econômica e cultural, principalmente do Sudeste, para se estar na nação, se deve acessar o que é produzido nesta região. Dada a globalização econômica com direta repercussão no cultural, os limites regionais passaram a se fazer pelo menos aparentemente tênues.

O pertencimento a um território, a uma região brasileira, nesse caso, acaba sendo algo que ganha maior complexidade dada a flexibilização das fronteiras. A subjetividade se 
torna atravessada pela presença do outro. Quem é de onde? De onde se está? Onde se fala? A linearidade definidora das regiões não corresponde à definição geográfica e mesmo política que a correspondem. Nesse jogo de presença/ausência de espaço/território a imagem que se traz do outro, que não está na evidência mediata do olhar, apresenta no discurso sua fulcral confluência de mediação.

Mesmo que as delimitações entre espaço/territórios se mostrem fugazes, não se pode negar a valoração desses lugares sociais. Desse modo, a posição de diferença, ou até deficiência entre centro e periferia, ainda que se busque, pautado na "ideologia dominante" da igualdade, disfarçá-la, não deixa de ser marcada.

Ao sabermos que, para se descrever e interpretar o discurso, faz-se imprescindível escavar no enunciado uma série de outros, deve-se:

[...] compreender o enunciado na estreiteza e singularidade de sua situação: de determinar as condições de sua existência, de fixar seus limites da forma mais justa, de estabelecer suas correlações com outros enunciados a que pode estar ligado, de mostrar que outras formas de enunciação exclui [...] mostrar [...] que singular existência é esta que vem à tona no que se diz e em nenhuma outra parte? (FOUCAULT, 2008, p. 31).

Desse modo, vimos que, ao trabalharmos com os conceitos de centro e periferia, outras palavras surgem. Numa cultura que repercute os valores eurocêntricos historicamente constituídos, quem está no centro estaria mais próximo ou, sobretudo, se identificada com a civilidade.

Onde estaria o "centro" se identificaria a "civilidade". Por outro lado, maior proximidade teria a periferia com a barbárie. Nessa concepção, mais assimilado estaria da civilidade aquele que, por estar no centro, talvez mais distante estaria de práticas bárbaras. Quem ocupa o lugar do centro maior acesso teria aos valores concebidos como fruto de cultura treinada para domar os instintos, ou seja, uma cultura sistematizada pela tecnologia grafocêntrica. Talvez, haja uma tendência em se pensar que muitos dos valores acessados por meio da cultura escrita favoreceriam um comportamento civilizado.

Pela valoração daquilo que se encontra ao centro, muito ou grande parte daquilo que ali se produz se realiza enquanto referência para o que está na periferia. Portanto, a civilização vinda do centro é esperada e pleiteada pela que se encontra ao longe. Os espaços periféricos teriam como alvo civilizatório chegar até o que se encontra no centro. No centro se teria a instância responsável pela produção, pelos produtos preferencialmente aceitos, por isto mais propício à visibilidade.

O sujeito aquém do centro, da civilidade, poderia ser identificado como bárbaro. Seria "o indivíduo, a etnia, a sociedade, a cultura que parece estranha aos valores ao mesmo tempo mais elevados e mais evoluídos da humanidade" (WOLFF, 2004, p. 25). Entre os civilizados e os bárbaros estaria "a oposição entre o Bem e o Mal" (WOLFF, 2004, p. 25). No entanto, esse autor vem referendar mais de uma possibilidade de se compreender a civilização ou mesmo a oposição civilização/barbárie.

Caracterizaria-se o civilizado tanto ao considerar-se o comportamento referente às necessidades naturais e à polidez social, quanto pelo desenvolvimento de um saber, de uma sensibilidade para a arte, ainda pela conduta ética e moral. Para se dizer quem é o civilizado e quem seria o bárbaro não se pode prescindir de um ponto de vista discursivo. Como verificamos as conceituações também se fazem ponto de vista, se utiliza a linguagem e se constrói uma perspectiva de definir-se algo, um objeto, uma estratégia de abordá-lo conforme o ponto de vista a ser defendido, alcançado. 
Dessa maneira, alguém que se faz bárbaro poderá ser revestido por uma identidade de civilidade e vice-versa. Assim, "em nome do fato de que se é (ou se pensa ser) portador da civilização, [...] que se é transformado em bárbaro" (WOLFF, 2004, p. 28). A posição de centro pode pautar-se numa superioridade resultante numa diminuição ou ainda num alijamento do distinto. Para que alguns façam-se centro outros podem ser colocados como marginalidade. Nem sempre a identificação com a margem pode-se fazer negação. Às vezes a condição marginal pode surgir como forma de garantir-se em determinados situações sociais. Busca-se a vitimização enquanto condição proporcionadora de um dado espaço.

$\mathrm{Na}$ definição do bárbaro como do civilizado deve-se recorrer a uma perspectiva temporal. Para adotar a visão da Nova História e adentrar-se na temporalidade alinear que desmonta a causalidade previsível e delimitadora do ontem e do hoje, seria necessário pensar a civilidade da cultura num jogo de retomadas múltiplas entre o hoje, o ontem e o amanhã, para além da fugacidade individualizadora e acomodante do agora. Renunciar a um tempo/espaço delimitado e reduzidamente modulado. Assim, se estudar o discurso é escavar a linguagem em sua historicidade dinâmica, alinear e paradoxal, busquemos a compreensão tripartida de tempo histórico, baseada em Braude:

[...] a análise das sociedades, economias e civilizações exigia que a pesquisa histórica operasse dentro de um tempo mais lento, pois os fenômenos que se manifestam dentro desses campos são marcados pelas regularidades, permanências, continuidades, repetições, isto é, ultrapassam o curto intervalo de tempo ocupado pelo acontecimento singular (ROCHA, 2003, p. 26).

Uma série de acontecimentos interpretados em suas relações de retomadas e transformações poderia levar à compreensão daquilo que se identificaria como civilização e barbárie numa dada cultura. Dessa maneira:

Uma concepção discursiva pode ser estabelecida por meio de enunciados que se fazem espécie de "cavaleiro errante", que ora "cavalgam" tranquilamente por entre discursos temporal e espacialmente próximos, ora "galopam" freneticamente por entre distantes e ausentes práticas discursivas (CUNHA, 2011, p. 106).

Considerando-se a relação discursiva produzida entre distintas regiões brasileiras, tendo por base a noção historicamente construída desses espaços a partir da base centro/periferia, parece encontrarmos produções discursivas referentes ao gênero jornalístico, especificamente do jornal impresso, que correspondem à fala, à voz, ao discurso produzido pela mídia do Sudeste brasileiro, tendo como objeto o estado do Pará.

O jornal impresso se realiza enquanto um "produto" vindo do "centro", a ser consumido pela "margem". Esse produto que na margem, por vir do centro, deve nele ficar. Aqueles que estão colocados ao centro, por estarem estabilizados nesse lugar, tendem a atribuir a condição de produto ao discurso jornalístico. O papel historicamente delimitado de "centro" para que permaneça precisa realizar estratégias de proteção para possíveis ameaças.

Nessas notícias jornalísticas encontramos determinados dizeres envoltos numa temática que parece se delimitar a um comportamento que poderia ser concebido como operando um distanciamento de uma marcada civilidade. Seriam textos que trazem como tema enunciativo vários acontecimentos referentes à "escravidão no Pará", ao "trabalho infantil em carvoarias". Isto poderia representar uma perspectiva discursiva que identificaria a cultura paraense como "bárbara"? 
Apesar da relação mais próxima do então estado do Grão-Pará com o centro do processo de colonização nos primeiros séculos do domínio português em relação ao Brasil, o próprio modo de colonização brasileira repercutiu na maior valoração do Sudeste brasileiro. A proximidade do estado do Pará relativo à matriz colonizadora refere-se não à média geral da população, mas sim àqueles de maiores posses, os que apresentavam a possibilidade de transitar entre a província e a coroa portuguesa.

No início da colonização brasileira foram os casais europeus, em maioria, que vieram para a colônia brasileira instalada via litoral Sul do Brasil, diferentemente da região amazônica, estado do Pará. Neste caso, os portugueses vieram, em grande parte, sozinhos. Este fato corroborou para a maior miscigenação nesta região.

Há relações de poder que imprimem valor ao espaço. Vê-se o outro diante da posição que se está historicamente colocado. A definição de um "centro" delimita "margens". A relação entre centro e margem irá estar na dependência dos valores colocados à prova. Então, podem estar as margens distantes ou próximas.

Analisando-se panoramicamente uma história escrita por historiadores sobre o estado do Pará, pode-se chegar à produção de algumas identidades que no tempo presente se inscrevem por outras instituições discursivas, como a mídia. Nessa história que desemboca no presente, desenham-se determinados discursos acerca da identidade paraense mais majoritariamente em circulação. Desacomodando-se quietamente de um lugar, o tempo histórico se movimenta entre sentidos vividos e a serem vivenciados, assim "é toda a História que é preciso mobilizar para a inteligência do presente" (BRAUDEL, 2007, p. 236). O passado surge "afoito", problematizado no presente.

O trabalho do historiador realiza-se, então, na inquietude de estar focado no passado, mas constituindo seus sentidos no presente. Assim, "a história não pára de encontrar o presente no seu objeto, e o passado, nas suas práticas. Ela é habitada pela estranheza que procura, e impõe sua lei às regiões longínquas que conquista, acreditando dar-lhes a vida" (CERTEAU, 2006, p. 46). No fazer do historiador, o passado é o novo que produz muitas indagações, assim o ontem se faz hoje atravessado pelos sentidos do agora.

Nesse contexto, é por uma rede complexa de identidades não somente do Brasil, mas da América Latina que se constitui a identidade paraense. Esta é forjada a partir das relações de acomodações e transformações diante de encontros e desencontros. Por aí se constroem as práticas culturais do branco colonizador, dos nativos indígenas e dos negros deportados que numa interação de dominação/acomodação produziram a cultura étnica paraense. Culturas diversas que em tensão trazem para a identidade paraense sua peculiaridade, mas também podem constituir pela miscigenação étnica uma singular identidade atravessada pela mestiçagem cultural.

\section{0 trabalho escravo e infantil no estado do Pará}

O estado do Pará ocupa a segunda colocação em relação aos demais estados brasileiros, isto considerando sua dimensão territorial. Esse estado é marcado por diversa e exuberante área fluvial, banhado seu território por imenso volume de água. Tendo em conta a demora característica do meio de transporte fluvial, torna-se mais dificultoso o trânsito interno de pessoas nesse estado.

No entanto, não somente por rios caracteriza-se o Pará, o grandioso território florestal amazônico paraense, que ainda no período colonial mostrava-se de difícil penetração e daí domínio, teve na década de sessenta do século passado sua dominação realizada de modo bastante direto por meio da construção de duas grandes rodovias. Para 
maior compreensão desse processo se faz importante reconhecermos um pouco da história interna do estado.

Podemos pensar para além da estrita divisão territorial e o estabelecimento de fronteiras internas ou mesmo externas que podem nos levar à reflexão acerca da relação entre o que seria lugar e o que se entenderia na contribuição de Certeau (2008, p. 201): "Um lugar é a ordem (seja ela qual for) segundo a qual se distribuem elementos nas relações de coexistência".

Para Santos (2002, p. 27), "um dos pontos de partida da ação humana no que tange a superação de suas necessidades de sobrevivência implicou, sempre, algum tipo de deslocamento". Movimento que provoca ação. Realizam-se discursos do trânsito entre os espaços. Os mapas são gerados dos lugares delimitados, estabelecidos pelas estabilidades políticas, pelas apropriações espaciais dos dispositivos de poder. A divisão em mesorregiões do estado do Pará não se detém nos aspectos físicos como também refere-se aos significados atribuídos aos estados.

Ação e movimento, lugar de ser, lugar para se ir, motivação espacial que faz o homem fazer-se discurso. As delimitações que geram mapas já se fazem a reprodução de uma disposição do espaço. Assim, no caso do Pará, teremos as mesorregiões do estado. Isto não se delimita aos aspectos físicos, mas também a uma significação atribuída aos lugares, refere-se ao modo como os sujeitos se percebem, se encontram/confrontam com os lugares.

Vejamos um mapa das mesorregiões do estado do Pará, para buscar compreender como as práticas de ocupação territorial, historicamente constituídas, resultaram no modo como se desenvolveu as relações de trabalho de maneira bem evidenciada mais caracteristicamente em duas mesorregiões desse estado.

Figura 1 - Mapa das Mesorregiões do Estado do Pará

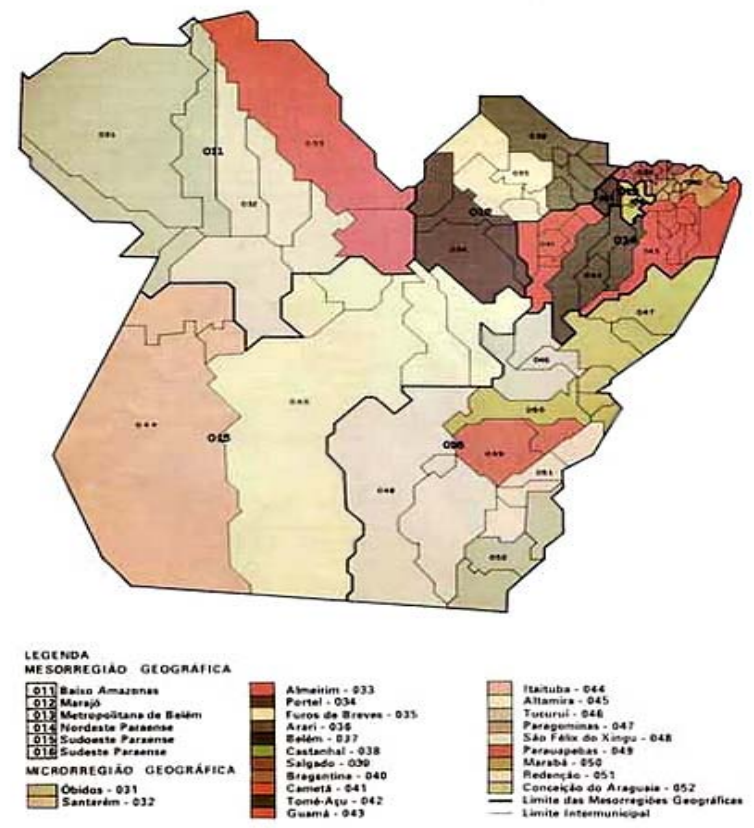

(FONTE: PARANÁ, 1996)

A migração foi resultante da política governamental militar e repressiva da década de sessenta do século XX. Na ditadura militar houve a implementação das grandes rodovias no estado do Pará, mais especificamente ligando o Sul/Sudeste e Nordeste do país 
ao Sudoeste paraense. Essa mesorregião, entre as demais, é a que maiores diferenças regionais apresenta, espaço de ocupação de imigrantes vindos do Sul, Centro-Oeste, Sudeste do país, fazendo usufruto de grandes territórios no Pará. Vieram ainda migrantes do Nordeste, ocupantes das pequenas propriedades. Dessa maneira, se os grandes 'fazendeiros', 'grileiros' e 'madeireiros', em sua maioria, eram os migrantes provenientes das regiões de maior poder econômico do Brasil; os 'trabalhadores rurais', os 'sem-terra' e os 'assentados' eram migrantes da região economicamente menos privilegiada.

No mapa acima $^{2}$ a região territorialmente menor é a que apresenta maior índice de desenvolvimento econômico e humano. Esta, denominada de região Metropolitana de Belém, é a que apresenta maior incidência populacional. Considerando as similaridades e diferenças, podemos atribuir maior identidade entre as regiões delimitadas na parte superior do mapa acima. São as regiões: Metropolitana, do Nordeste paraense, do Marajó e do Baixo-amazonas. A região do Marajó e o Nordeste paraense são culturalmente mais próximas. Já o Baixo-amazonas se faz distanciada pelos rios que caracterizam o estado, principalmente no que tange à geografia das regiões mais ao Oeste do Pará.

As duas mesorregiões que se localizam abaixo do mapa acima, Sudeste e Sudoeste paraense, justamente pela localização geográfica, constituíram-se em sua maior parte pelo fluxo migratório resultante do incentivo governamental militar, materializado na construção das rodovias Santarém-Cuiabá e Transamazônica. Pede nosso destaque a mesorregião do Sudoeste formada por duas microrregiões bastante populosas: Altamira e Itaituba. Estas apresentam um grande potencial econômico dada a própria construção de uma das maiores hidrelétricas do país: Belomonte ${ }^{3}$.

Embora o regime escravista não tenha deixado de ocorrer no estado do Pará, a produção dessa forma de exploração humana no Pará foi diferente daquela observada em outros estados do Brasil. A geografia física da região dificultou o tráfico negreiro para o estado do Grão-Pará, tanto pela distância da costa, do litoral atlântico, quanto pela própria paisagem caracterizada de modo bastante singular pela densidade florestal da Amazônia.

Dessa maneira, pela dificuldade de mão-de-obra negra para o trabalho escravo, foi aos nativos indígenas que recorreram os colonizadores para realizar tal tarefa. Esse processo foi marcado pela resistência. Isto dado o nomadismo característico desses povos, como também se considerando o próprio paradigma cultural indígena por se confrontar com o trabalho e com a atividade produtiva dos portugueses.

O movimento escravista na Amazônia paraense marcado nos primeiros séculos da colonização pela resistência indígena parece ter sido potencializado com a construção das grandes rodovias (talvez num confronto com a natureza marcadamente fluvial da região). Isto porque devido à própria desigualdade regional brasileira, essa parte parcamente ocupada do estado do Pará foi palco acirrado de grandes diferenças socioculturais, e mesmo distintas e até excludentes formas de relações históricas, conforme veremos a seguir.

\footnotetext{
${ }^{2}$ Dados retirados do IBGE (Instituto Brasileiro de Geografia e Estatística), referentes aos censos 2010, 2011. Dados também retirados do IDESP (Instituto de Desenvolvimento Econômico e Social do Pará).

${ }^{3}$ Segundo Cunha (2011, p.59) Na primeira, há em torno de 247.642 habitantes em oito municípios: Altamira, Anapu, Brasil Novo, Medicilândia, Pacajá, Senador José Porfírio, Uruará e Vitória do Xingu. Já a microrregião de Itaituba apresenta cerca de 272.781 habitantes. É cortada por duas importantes rodovias, a BR-163 (Rodovia Cuiabá-Santarém) e a BR-230 (Rodovia Transamazônica). Encontram-se nessa microrregião seis municípios: Aveiro, Itaituba, Jacareacanga, Novo Progresso, Rurópolis e Trairão
} 


\section{0 discurso da barbárie ou notícias de uma realidade tempo- espacialmente distante}

Analisemos o texto abaixo e algumas manchetes e chamadas de notícias a respeito do trabalho escravo no estado do Pará ${ }^{4}$. Nossa busca se fará principalmente em torno da produção da identidade construída pelo jornal, tanto dos sujeitos que são escravizados quanto daqueles que os escravizam. Também se fará pertinente a indagação em torno de como se constrói a identificação do estado do Pará com essa temática.

A notícia veiculada na Folha de S.Paulo ${ }^{5}$, em 28 de agosto de 2002, apresenta como título em destaque de cor azul o nome do estado do PARÁ. Sequente ao nome, designativo do estado brasileiro, temos duas chamadas. A primeira constituída de dois enunciados e a segunda de um:

Quadro 1 - Sequência discursiva para análise $01^{6}$

São Paulo, quarta-feira, 28 de $\quad$ agosto de 2002
FolHa de S.PALlo braSil
$\quad$ PARÁ
Grupo era mantido em regime semelhante à escravidão; Estado teve $\mathbf{6 5 0}$ casos
neste ano
Fiscais libertam 136 trabalhadores
MAURÍCIO SIMIONATO
DA AGÊNCIA FOLHA, EM BELÉM

(FONTE: SIMIONATO, 2002)

O substantivo grupo iniciando a primeira chamada deixa claro haver mais de um ser humano sendo escravizado. O número de pessoas escravizadas vem ser esclarecido já na segunda chamada. Observa-se uma relação de correspondência semântica entre o substantivo inicial da primeira chamada grupo e parte do predicado da segunda, ou seja, os 136 trabalhadores. Este efeito de anúncio, do todo e complementaridade das partes, parece criar a necessidade da busca da informação. Na progressão do texto, busca-se persuadir o leitor provável para a interação jornalística.

Também entre a locução verbal era mantido da primeira chamada e o verbo libertam núcleo do predicado da segunda verifica-se a mesma relação de dependência semântica entre os enunciados. Então, se o grupo era mantido é porque já não se encontra na condição de escravo, ou ainda semelhante à escravidão. Desse modo, o que se anunciará na chamada seguinte já se encontra implicado na primeira, ou seja, a liberdade de certo

\footnotetext{
${ }^{4}$ Os textos jornalísticos analisados constituem o corpus de nossa tese de doutoramento intitulada "Tão longe, tão perto: a identidade paraense construída no discurso da mídia do Sudeste brasileiro". Foi feito um recorte referente a notícias produzidas num período de 12 anos do jornal paulista 'Folha de S.Paulo'

${ }^{5}$ Todas as palavras retiradas dos textos jornalísticos analisados, ou seja, referente ao corpus, foram escritas em itálico. O uso de aspas duplas, além das citações bibliográficas no corpo do texto, aparece para destacar um termo de modo explicativo.

${ }^{6}$ Para cada notícia/manchete analisada daremos o nome de sequência discursiva. Neste artigo trouxemos para análise seis sequencias discursivas.
} 
modo já vinha anunciada. Essa relação de informação pré-enunciada e posteriormente dita parece caracterizar o discurso jornalístico. Registre-se também o distanciamento histórico oficial vivido naquele estado sugerido pela materialidade discursiva. Isto porque teria uma forma de relação trabalhista que embora não fosse a já anacrônica escravidão, oficialmente ultrapassada, se assemelhava a esta.

Verifica-se ainda entre as duas chamadas, dois numerais cardinais, respectivamente 650 e 136. Na primeira o número antecipa uma totalidade. Na segunda aparece um número que apesar de menor do que o primeiro já se mostra grande. Assim, se pode chegar à seguinte produção de sentido: se grande é o número de trabalhadores nesse regime encontrado somente em uma fazenda, maior é a totalidade de trabalhadores já deflagrados naquela situação considerando-se um pouco mais da metade do ano, no mês de agosto. Vejamos o primeiro parágrafo do texto:

Quadro 2 - Sequência discursiva para análise 02

Um grupo de 136 trabalhadores rurais mantidos em regime análogo ao da escravidão no sul do Pará ${ }^{7}$ foi libertado ontem. O Estado é recordista em casos desse gênero, com pelo menos 650 registros neste ano $-62,5 \%$ a mais do que no mesmo período de 2001 , até agosto, quando havia 400.

(FONTE: SIMIONATO, 2002)

Nesse enunciado o substantivo recordista além de explicitar a superação numérica da escravidão no Pará, ainda deixa o sentido de que houve um crescimento ou ainda um aumento exacerbado nesse regime de trabalho, que historicamente deveria estar superado. A leitura possibilitada pelo enunciado é de que algo que já deveria estar superado a cada ano que passa tem se intensificado no estado do Pará. Dado o caráter não civilizado ou mesmo bárbaro da relação trabalhista divulgada pelo enunciado parece se desenhar uma maior identificação do estado com a barbárie.

A Secretaria de Segurança Pública do Pará é colocada em cena na enunciação jornalística, vejamos:

\section{Quadro 3 - Sequência discursiva para análise 03}

A Procuradoria do Trabalho verificou que as carteiras de trabalho estavam assinadas, mas que os trabalhadores não eram pagos e viviam em condições insalubres.

O dono da fazenda não foi localizado ontem. A Secretaria de Segurança Pública do

Pará informou que a questão não é de responsabilidade do órgão. (Grifo nosso)

(FONTE: SIMIONATO, 2002)

O dizer de não responsabilização da Secretaria de Segurança Pública do Pará parece destacar o descaso da administração pública estadual, relativo ao trabalho escravo. Isto fica mais evidenciado se considerarmos outro enunciado na mesma notícia que destaca o compromisso dos fiscais federais, pois estes representantes do poder federal, diferentemente do poder estadual, encontram-se há nove dias à espera do proprietário da

\footnotetext{
${ }^{7}$ Toda vez que houver referência à mesorregião Sul no corpus, consideraremos a mesorregião Sudeste do estado. O discurso comum tende a denominar esta mesorregião como Sul. Muitas vezes também a mesorregião Sudoeste é denominada dessa maneira.
} 
fazenda onde se pratica o trabalho escravo. Os fiscais federais buscavam uma explicação para o tipo de trabalho exploratório executado na fazenda localizada no Sudoeste paraense. A irresponsabilidade do Governo Estadual parece convergir para outros textos que enunciam o estado do Pará como Terra sem lei, funcionando como uma espécie de seção de muitas notícias encontradas em matérias desse mesmo jornal impresso.

Em outro enunciado se verifica outras atitudes relacionadas aos trabalhadores no/do Pará que também alcançam de modo mais efetivo um tom bárbaro, vejamos:

\section{Quadro 4 - Sequência discursiva para análise 04}

"Os trabalhadores são iludidos e chegam em caminhões de gado. São vigiados por pistoleiros e trabalham para pagar suas dívidas contraídas na própria fazenda", disse o coordenador da Comissão de Justiça e Paz da CPT no Pará, padre Adriano Sella.

(FONTE: SIMIONATO, 2002)

Neste caso vimos o modo de transporte em que se levam os trabalhadores, ou seja, em caminhões de gado. Além de não receberem pelo trabalho executado, são levados ao setor de trabalho em condições insalubres como se animais fossem. Os trabalhadores, sujeitos desse discurso jornalístico, exercem sua força de trabalho somente para uma alimentação. No entanto na lógica desumana e exploratória da relação, o alimento sempre parece valer mais do que qualquer esforço dos trabalhadores expostos a esta condição. Então, os trabalhadores são transportados em condições desumanas e ainda sofrem atitudes repressivas de sujeitos executores de ações ilegais, que parece remontar um passado bárbaro.

Os pistoleiros, termo que parece apontar para uma matança generalizada e impune, num lugar distanciado espacial e temporalmente do pretenso e delimitado centro em oposição à periferia. Tal lugar parece ratificar estes homens como profissionais estabelecidos e naturalizados do crime, de uma terra distanciada dos valores jurídicos e até mesmo policiais de uma legalidade civilizada.

Também, tal como na primeira manchete, no caderno brasil, vejamos o título e a manchete da notícia a seguir, que fortalece discursivamente a postura ultrapassada observada no estado do Pará a respeito da temática evidenciada:

Quadro 5 - Sequência discursiva para análise 05

São Paulo, domingo, 01 de junho de 2003 Folha de s.Pallo brasil

PARÁ

\section{Prefeito é acusado de trabalho escravo}

(FONTE: PREFEITO..., 2003)

Além de se praticar o trabalho escravo no estado do Pará, também observa-se uma incompetência dos órgãos governamentais para punir aqueles que cometem esse crime. Nesse enunciado o governo do/no Pará aparece (o que mais realça uma prática não civilizada no estado) promovendo o trabalho escravo. Pela enunciação, no Pará o prefeito pratica o trabalho escravo, desse modo, esse enunciado pode levar à seguinte produção de sentido: além de se praticar o trabalho escravo no Pará. Este tipo de trabalho é promovido 
pelas próprias autoridades. Estes seres humanos se mostrariam como síntese de uma sociedade marcada pelo distanciamento de direitos sociais e humanos alcançados. Esse viés interpretativo se ratifica na memória discursiva do leitor do jornal, ao reconhecer o 'Pará' como recordista nesse tipo de exploração da dignidade e direitos humanos.

Apesar da sequência da notícia levar à produção de outras ordens de sentido ao texto, pois irá se demonstrar algo que se relaciona ao que vimos antes, ou seja, ao fato de o praticante da exploração trabalhista e humana não ser natural nem morador do Pará. Isto também demonstra a grande circularidade de migrantes e sujeitos donos proprietários das terras, fruto do movimento de ocupação motivado pela construção das grandes estradas de acesso ao Sudeste e Sudoeste paraense.

Mostraremos a seguir alguns textos jornalísticos do mesmo corpus construído metodologicamente para a pesquisa acerca da produção da identidade sobre o estado do Pará. Neste caso, referindo-se a outro tipo ainda mais comprometedor daquilo que poderia ser pensado como civilidade: o trabalho infantil em condições insalubres e ameaçadoras da dignidade ou mesmo da sobrevivência humana. Nessa situação teríamos duas atitudes distantes da civilidade, além de se promover um tipo de trabalho que sob quaisquer condições seria ilegal, atividade feita por menores, ainda se colocam seus praticantes, crianças, em condições insalubres.

Quadro 6 - Sequência discursiva para análise 06

São Paulo, segunda-feira, 12 de novembro de 2001
FolHa de S.PAulo Cotidiano
INFÂNCIA
Desde novembro de 97, pelo menos 20 menores queimaram mãos e pés ao
cair em covas de terra em Paragominas
Fornos de carvão mutilam crianças no PA
ULISSES CAMPBELL
FREE-LANCE PARA A AGÊNCIA FOLHA, EM PARAGOMINAS

(FONTE: CAMPBELL, 2001)

A publicação divulgada no caderno cotidiano é intitulada Infância. O caderno parece sugerir um tema rotineiro, corriqueiro e até mesmo comum a uma cidade, talvez a condição que se possa identificar à cidade do estado do Pará. As chamadas de notícia se realizam em dois enunciados. No primeiro se verifica uma referência temporal: desde novembro de 97. Desse modo, o fato de a notícia ter sido veiculada quatro anos depois, ou seja, em novembro de 2001, implica-se então que, neste período, pelo menos 20 menores tiveram queimados mãos e pés. Nesse caso, o uso da expressão quantitativa pelo menos aponta para uma indicação de crescimento nos índices de lesões mutiladoras resultante do trabalho inseguro praticado por crianças.

$\mathrm{Na}$ sequência da mesma formulação enunciativa da notícia, se irá anunciar uma informação delimitadora do tema noticiado: os menores queimaram pés e mãos por terem caído em covas de terra em Paragominas. Por conseguinte a outra chamada da notícia irá realmente explicitar a temática do trabalho infantil. Então, na chamada seguinte, se 
esclarece que as covas de terra são fornos de carvão. Assim, não foi em qualquer cova de terra que os menores se queimaram, mas foram em fornos de carvão. Desse modo, se há fornos de carvão é porque se pratica a ação de trabalhar nestes. Então, fica implícito que os menores estavam em atividade de trabalho, além de ilegal, por serem crianças, ainda se fazia insalubre.

Ainda na segunda chamada verifica-se a extensão metonímica da prática executada pelos fornos de carvão, ampliando a ação espacial em que está inclusa a atividade de fazer carvão, portanto, de realização do insalubre trabalho infantil. Fica estendida a localização territorial das crianças, e não são somente às de Paragominas, mas sim as do $P A$ : as crianças do Pará trabalham e são mutiladas por esse trabalho. A produção de carvão aciona outros efeitos de sentido, onde haveria produção de carvão haveria árvore, ou ainda devastação, desmatamento florestal.

Daí, teríamos outras ações que distanciariam o estado do Pará de atitudes mais

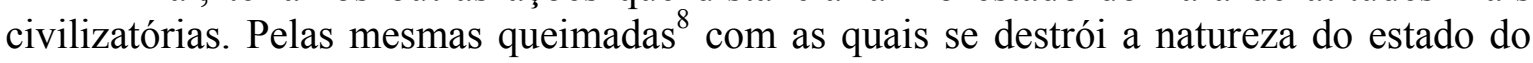
Pará se pratica o crime da exploração do trabalho infantil. Assim, se é pelas queimadas que se destrói a natureza do estado do Pará, também por ela se destroem as 'crianças', sua infância. Além de expressas no enunciado escrito, as crianças são visualmente mostradas, imprimindo-se um realismo ao que é dito, fazendo-se o leitor testemunhar aquilo que a enunciação jornalística enunciou:

Figura 2 - Jarmison dos Santos, 11, que aos dois anos queimou os pés ao cair em um forno e que hoje só consegue usar calçados especiais

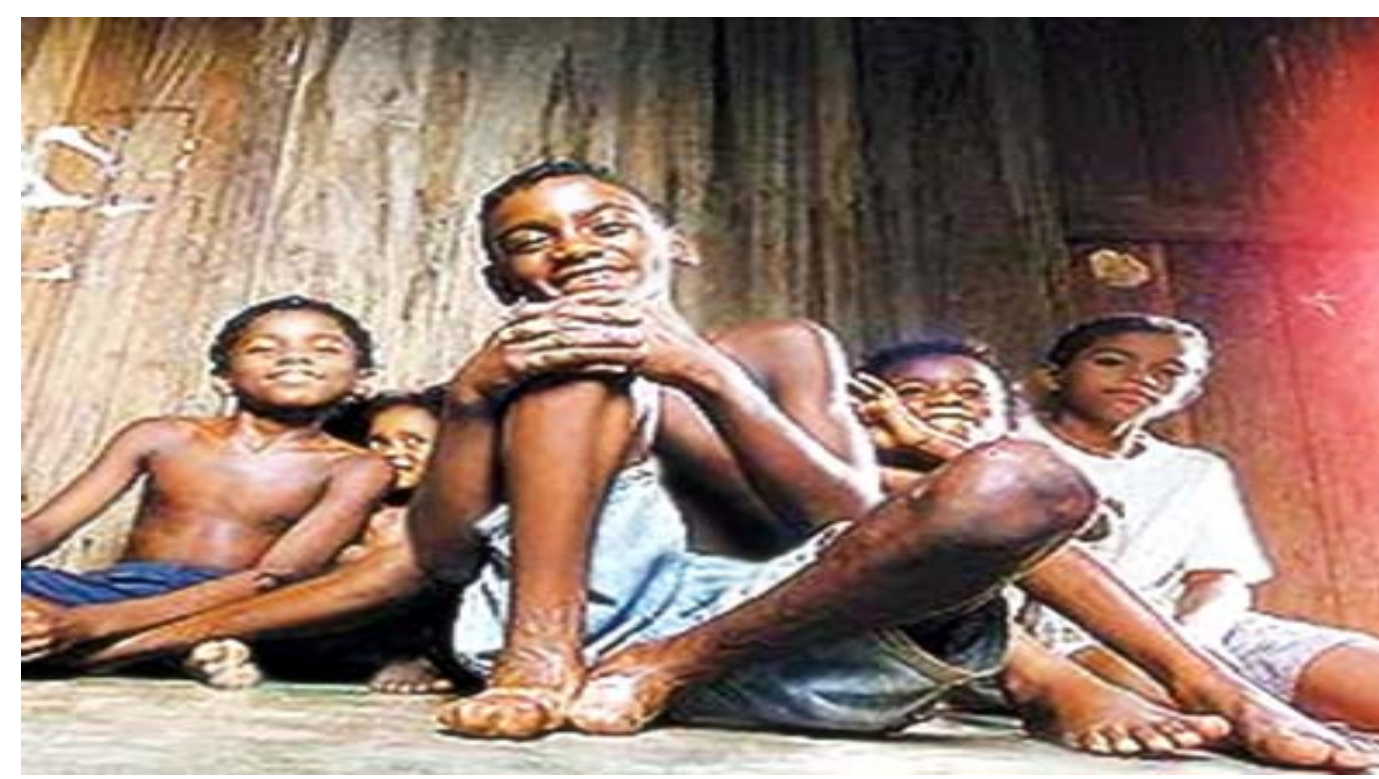

(FONTE: BERGAMO, 2001)

$\mathrm{Na}$ imagem acima, fica destacada, em primeira dimensão, o contraste entre o sorriso de criança exultante de esperança e a mutilação nos pés de Jarmison dos Santos. A pele negra ou mesmo mestiça deste menino revela uma memória de exploração brasileira. Ao negro historicamente no Brasil coube o papel de realizar serviços em condições exploratórias ou mesmo desumanas. A cor da pele negra de Jarmison não deixa de apontar para uma identificação social de baixo poder econômico. Ainda a própria moradia

\footnotetext{
${ }^{8} \mathrm{Na}$ pesquisa de tese de doutoramento, conforme já esclarecemos anteriormente, analisamos discursivamente as várias temáticas indicadoras da identidade paraense, dentre as quais a relativa ao meio ambiente, ao desmatamento e à queimada.
} 
demonstrada na foto materializa o lugar de habitação que identifica não somente uma condição social como também o fato de ser produzida por uma matéria prima característica da região com disponibilidade em madeira.

\section{A barbárie apontada na produção dos sentidos reiterativos da mídia}

A produção de sentido do texto jornalístico tende a se concentrar na manchete e chamada de notícia. O percentual de leitores que acaba acessando essa parte da notícia é bem maior pela própria exposição de leitura a que são submetidas às manchetes, por exemplo. Os leitores de passagens pelas bancas de revistas e jornais, pelas esquinas e locais de exposição acabam constituindo uma produção de sentido tomando a parte pelo todo. Claro que, muitas vezes, esta é propositalmente a intenção do veículo de comunicação, favorecer determinadas produções de sentido. Assim, produzindo leituras fragmentadas.

Mas é na sequência da notícia que poderá se produzir outros sentidos. No caso da notícia destacada anteriormente, aquele sujeito que realiza o trabalho escravo não é prefeito no Pará, mas em uma cidade mineira. Ainda nesse sentido delineado pela progressão textual, pode-se inferir o fato de que qualquer sujeito, mesmo que exerça uma atividade política, ainda de autoridade administrativa num estado do Sudeste brasileiro, no Pará pode exercer uma atividade de ilegalidade ou mesmo humanamente ultrapassada, arcaica: a promoção do trabalho escravo. O Pará, assim, seria permissivo na promoção de qualquer atividade, ainda que humanamente bárbara. Então, o sujeito prefeito ainda que exerça a atividade política de maior poder municipal em seu estado distante, no caso Minas Gerais, encontraria no estado do Pará as condições para exercer a atividade escrava.

O estado do Pará é ressaltado de modo repetido pela posse indiscriminada e conflitante da terra. Por meio deste crime outros são cometidos, não somente resultando no trabalho escravo como também no trabalho infantil, ações enunciadas como "arcaicas", identificadas com a "barbárie" por determinar, além de mortes violentas, no caso dos conflitos que levam à morte violenta, tanto de lideranças do campo quanto de trabalhadores rurais, ou ainda levar a sequelas tanto físicas quanto psicológicas no ser humano.

Portanto, a enunciação do jornal impresso do Sudeste brasileiro noticia de modo bastante repetitivo uma direta relação entre a própria geografia física do estado do Pará e a prática até mesmo indiscriminada do trabalho escravo e infantil. Isto, então, pelo estado ser definido pela existência de densa floresta que, embora com sérios índices de devastação, ainda se faz distanciado de uma paisagem marcadamente urbanizada. Por isto propício à atividade escrava.

Mesmo que venha enunciado nos textos aqui referendados (e outros analisados) que a prática do trabalho escravo seja feita em grande parte por imigrantes, sujeitos ocupantes das terras do estado, mas não nativos, essa referência não se mostra destacada, ao contrário se faz atenuada ou mesmo passível de não ser visibilizada.

Dessa maneira, ainda que se informe a procedência dos que promovem o trabalho escravo e mesmo o trabalho infantil como também os sujeitos principais do conflito agrário repetidos em outras notícias produzidas e veiculadas por este mesmo jornal em pauta, a própria semiologia do texto jornalístico parece priorizar um viés interpretativo dos potenciais leitores do jornal, no sentido de identificar tais práticas com o estado do Pará. Identidade mais ainda realçada e assimilada ao Pará quando se verificam enunciações que também identificam o estado com as práticas do desmatamento e das queimadas.

Na prática enunciativa do jornal Folha de S.Paulo parece termos então um jogo enunciativo que, para além de anunciar uma temática reincidente no estado do Pará, 
constrói um discurso que potencializa uma certa identidade a respeito desse estado. Uma identidade produzida no fulcro das diferenças históricas das regiões brasileiras. Uma identidade tecida nas palavras de uma mídia em foco pelo poder que promove visibilidade.

\section{REFERÊNCIAS}

AGAMBEN, G.. O que é o contemporâneo? e outros ensaios. Tradução Vinicius Nicastro Honesko. Chapecó, SC: Argos, 2009.

BARONAS, R. L. Formação discursiva em Pêcheux e Foucault: uma estranha paternidade. In: NAVARRO-BARBOSA, P. ; SARGENTINI, V. M. (Org.). Foucault e os domínios da linguagem: discurso, poder, subjetividade. São Carlos: Claraluz, 2004, p. 45-62.

BAUMAN, Z. Modernidade Líquida. Rio de Janeiro: Jorge Zahar Ed., 2001.

BRAUDEL, F. Escritos sobre a história. Tradução J. Guinburg e Tereza Cristina Silveira da Mota. São Paulo: Perspectiva, 2007.

BERGAMO, M. In: CAMPBELL, U. Desde novembro de 97, pelo menos 20 menores queimaram mãos e pés ao cair em covas de terra em Paragominas. Folha de S. Paulo, Folha imagens, São Paulo, v ou n.12, nov. 2001. Cotidiano. Disponível em: http://www.folha.uol.com.br. Acesso em: 10. jul. 2010.

CANCLINI, N. G. Consumidores e Cidadãos: conflitos multiculturais da globalização. Tradução Maurício Santana Dias . 7. ed. Rio de Janeiro: Ed. UFRJ, 2008.

CERTEAU, M. A Escrita da História. 2. ed. Tradução Maria de Lourdes Menezes. Rio de Janeiro: Forense, 2006.

CERTEAU, M. A invenção do cotidiano. Tradução Ephraim Ferreira Alves. 15.ed. Petrópolis, RJ : Vozes, 2008.

CORACINI, M. J. Discurso, sujeito e subjetividade. In: SANTOS, J. B. C et al. Sujeito e Subjetividade: discursividade contemporâneas. Uberlândia: EDUFU, 2009. p. 25-42.

CUNHA, M. A. D. Tão longe, tão perto: a identidade paraense construída na mídia do Sudeste Brasileiro. 2011. Tese (Doutorado em Linguística e Língua Portuguesa) Programa de Pós-Graduação em Letras, Universidade Estadual Paulista Júlio de Mesquita Filho. Araraquara, 2011.

FERNANDES, C. A.; ALVES JÚNIOR. A. Mutações da Noção-Conceito de Sujeito na Análise do Discurso. In: SANTOS, J. B. C et al. Sujeito e Subjetividade: discursividades contemporâneas. Uberlândia, EDUFU, 2009. p. 103-149.

FOUCAULT, M. A Arqueologia do Saber. 7. ed. Rio de Janeiro: Forense Universitária, 2008 .

GREGOLIN, M. R. Foucault e Pêcheux na análise do discurso: diálogos e duelos. São Carlos: Claraluz, 2004.

GREGOLIN, M. R. Linguagem e História: relações entre Linguística e Análise do Discurso. In: SANTOS, J. B. C et al. Sujeito e Subjetividade: discursividade contemporâneas. Uberlândia: EDUFU, 2009. p. 33-58.

HALL, S. A identidade cultural na pós-modernidade. Tradução de Tomaz Tadeu da Silva e Guacira Lopes Louro. 11. ed. Rio de Janeiro: D P\&A, 2006. 
INSTITUTO BRASILEIRO DE GEOGRAFIA E ESTATÍSTICA (IBGE). Censo demográfico 2010. Disponível em: <http://www.sie.pa.gov.br/i3geo/relatorio.php> Acesso em: 05 abr. 2011.

INSTITUTO BRASILEIRO DE GEOGRAFIA E ESTATÍSTICA (IBGE). Censo demográfico 2010. População residente por situação do domicílio e sexo-Sinopse. Disponível em: <www.Sidra.ibge.gov.br>. Acesso em: 30 set. 2011.

INSTITUTO BRASILEIRO DE GEOGRAFIA E ESTATÍSTICA (IBGE). Censo demográfico 2011: População residente, por lugar de nascimento e sexo, segundo as Mesorregiões, as Microrregiões e os Municípios - Pará. Rio de Janeiro, 2011.

INSTITUTO DE DESENVOLVIMENTO ECONÔMICO, SÓCIO AMBIENTAL DO ESTADO DO PARÁ (Idesp). Área desflorestada $\mathrm{em}^{\mathrm{km}^{2}}$ segundo Mesorregião -2000 2009. Disponível em: <http://www.sie.pa.gov.br/i3geo/relatorio.php>. Acesso em: 05 out. 2001.

INSTITUTO DE DESENVOLVIMENTO ECONÔMICO, SÓCIO AMBIENTAL DO ESTADO DO PARÁ (Idesp). Evolução da quantidade produzida de açaí (toneladas). Disponível em: <http://www.sie.pa.gov.br/i3geo/relatorio.php>. Acesso em: 30 out. 2001.

INSTITUTO DE DESENVOLVIMENTO ECONÔMICO, SÓCIO AMBIENTAL DO ESTADO DO PARÁ (Idesp). Evolução do rebanho bovino (cabeças). Disponível em: $<$ http://www.sie.pa.gov.br/i3geo/relatorio.php>. Acesso em: 30 out. 2001.

MAPA político do Estado do Pará. Revista Nosso Pará, Belém, n. 2, 1996. Disponível em: $<$ http://www.tvliberal.com.br/revistas/npara/edicao2/index.htm>. Acesso em: 14 jan. 2011.

MARCONDES FILHO, C. O capital da notícia: jornalismo como produção social da segunda natureza. 2. ed. São Paulo: Ática, 1989.

MARTIN-BARBERO, Jesús. Dos meios às mediações: comunicação, cultura e hegemonia. Tradução Ronaldo Polito e Sérgio Alcides. 6. ed. Rio de Janeiro: Ed. UFRJ, 2009.

PÊCHEUX, M. Discurso, estrutura ou acontecimento. Campinas, SP: Pontes, 2002.

PREFEITO é acusado de trabalho escravo. Folha de S. Paulo On-line, São Paulo, 01, jun. 2003. Brasil. Disponível em: <http://www.folha.uol.com.br>. Acesso em: 10/11 jul. 2010.

PARANÁ. Resolução, $\mathrm{n}^{\circ} 51$ de 31.07.89. Reprodução a partir das informações constantes no Projeto de Regionalização Administrativa do Estado do Pará, editado pela SEPLAN/IDESP em 1992. Revista Nosso Pará, 1996.

ROCHA, A. P. Tempo histórico e civilização material. In: LOPES, M. A. (Org.). Fernand Braudel: tempo e História. Rio de Janeiro: Ed. FGV, 2003. p. 21-34.

SANTOS, D. A reinvenção do espaço: diálogos em torno da construção do significado de uma categoria. São Paulo: Ed. UNESP, 2002.

SIMIONATO, M. Grupo era mantido em regime semelhante à escravidão. Folha de São Paulo On-line, São Paulo, n. 28 ago. 2002. Brasil, Pará. Disponível em: $<\mathrm{http}: / / \mathrm{www}$.folha.uol.com.br>. Acesso em: 12 jul. 2010.

SOUZA JÚNIOR, J. A. de S. O projeto pombalino para a Amazônia e a Doutrina do 'Índio-Cidadão'. In: ALVES FILHO, Armando et al. Pontos de história da Amazônia. Belém: Produção Independente, 1999. v.1. p. 23-33. 
WOLFF, Francis. Quem é o bárbaro? In: NOVAES, A. (Org.). Civilização e barbárie. São Paulo, SP: Companhia das Letras, 2004. p. 21-47.

Recebido em fevereiro de 2013.

Aprovado em abril de 2013. 